\title{
Ergonomic Design of a Scrap Compactor for Small Scale Industries
}

\author{
Bobby P Paul ${ }^{1, a}$, S. Darius Gnanaraj ${ }^{1, b^{*}}, J$ Chandran ${ }^{2, c}$
}

${ }^{1}$ Karunya University, Coimbatore- 641114, India.

${ }^{2}$ Vishal Training Academy, Coimbatore 641004, India.

abobbyppaul@gmail.com, bdarius@karunya.edu, cwppl@md3.vsnl.net.in

Key Words: Scrap, Ergonomics, Compactor, Costing, Hydraulics, CAD.

\begin{abstract}
Concept design of a scrap compactor is presented. Required data for the design of the scrap compactor, the hydraulic circuit, the compression ratio, force required for compression are collected from literature. The current practice of scarp removal and storage in a small scale industry is shown. The calculations for arriving at the force required for compaction is presented. The hydraulic circuit diagram and testing of the circuit in a pneumatic test bench are explained. Cost of the prototype and the break even period are discussed. Ergonomic principles and safety due to usage of scrap compactor are highlighted.
\end{abstract}

\section{Introduction}

The management of scrap is one of the most avoided and difficult part in an industry. The scrap from lathe, drilling machine and milling machine lie on the shop floor makes the work difficult. Also the scrap takes more space than required. Manual handling of scrap material poses problem in industries. More volume and weight can be transported if the scrap material is compressed. This method also helps in selling scraps and recycling economically.

For compacting the scrap, different technologies can be used. Mechanical, Hydraulics or Pneumatic systems can be developed to compress the scrap. Hydraulic technology is selected as it can deliver more force on the scrap to compress. Pictures of the scraps on the floor and the dumping yard were recorded. A general study was conducted to find the time taken to remove the scrap and the cost behind the removal. A general question and answer session was conducted to take feedback from the employees and the management about the current scrap management.

This paper reports the approach of designing the scrap compactor and to develop a concept by incorporating Ergonomic principles. The concept developed is further developed in a detailed way to make the machine to do the job efficiently and effectively. A detailed costing is done to find the cost of the machine. These details will help small scale industries to install a scrap compactor.

\section{Literature Survey}

Liu Jianxiong et al deal with the design and development of a scrap shredder and compactor for End of Life vehicles and Home appliances. A detailed description of design, development and testing of the machine is illustrated [1]. TORO University technical training manual on Hydraulics explains all about hydraulics and hydraulic circuits. The required circuit of the project is developed with the help of this book [2]. Darius Gnanaraj explains the scope of making a scrap Compressing Machine for small scale industries. It describes all about the different scrap compactors available and its relevance in the industry for better safety, productivity and ergonomics. It also highlights about the accumulation of scrap in the industry and the problems involved in disposal of the scrap. Ideas for designing a scrap compactor using ergonomic principles at a lower cost are also illustrated in this paper. It also considers the best postures of the people collecting the scrap [3]. Scrap Metal Baling Press (SMB-F125) Supplied by: Enerpat Machine Co., Ltd gives the specification for scrap room and the maximum force that can be applied for that scrap room [4]. Electronic source Hydraulics and Pneumatics gives the picture of the Hydraulic Circuit [5]. Electronic source IQS 
Directory gives the details on scrap compression ratio [6]. Improvements in processing technologies and machinery as well as continued strong demand for scrap metal contributed to productivity gains according to Sieling [7].

\section{About the Company}

The company in which the study was conducted started in the year 1986. They are successfully catering to Engineering industries for over a decade now. They have technical expertise, strict quality control, competitive pricing and prompt delivery can help other companies to reduce delivery time and increase its productivity. The company makes Standard Mould Bases, Manufactures Precision Components, and Assembles Sub-Assemblies for Printing, Paper, Textile, Aero \& Oil type of Machineries Worldwide. The company has all the required facilities for machining and inspection, equipped With CNC Machining Centres \& Other Machineries, CMM \& Height Master. They manufacture as per Customer Drawings \& Specifications and has qualified personnel to meet any technical demand. This paper reports the ergonomic design of a scrap compactor to compress the scrap material coming out from small machineries like lathes, drilling machines, milling machines etc.

\section{Uses of Scrap Compactor}

- $\quad$ Scraps can be compressed to create small blocks.

- $\quad$ Space can be saved in the industry.

- $\quad$ Cost of scrap transportation can be saved.

- $\quad$ More scrap material can be transported.

- $\quad$ Scrap recycling will become easier.

\section{Current Practice of Scrap Removal and Storage in the Industry}

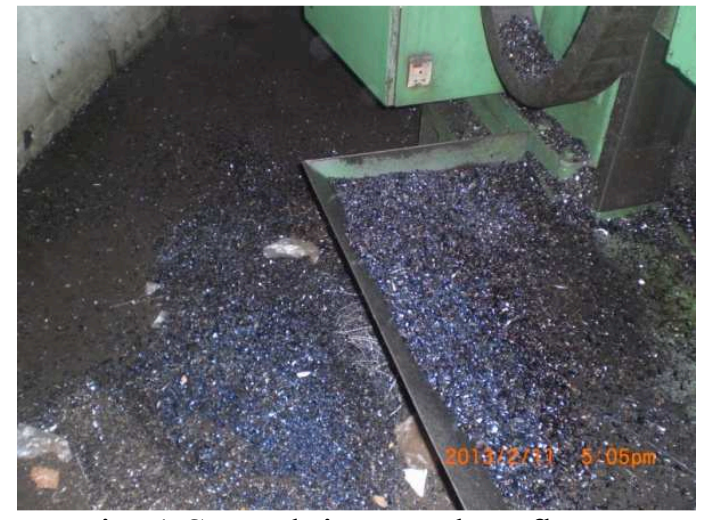

Fig. 1 Scrap lying on shop floor

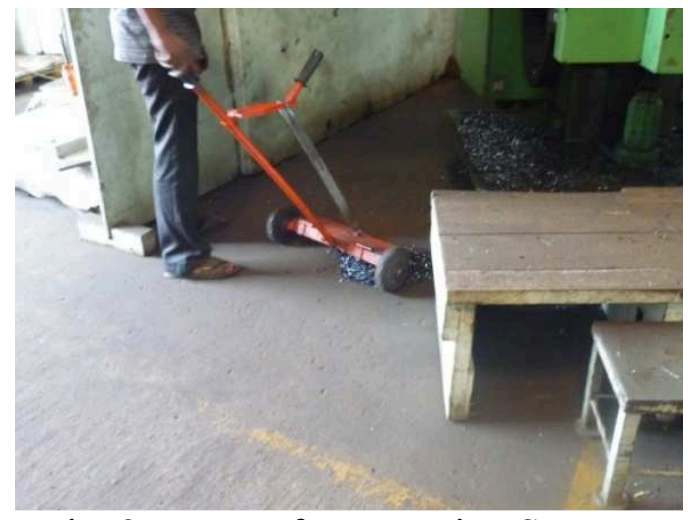

Fig. 2 Magnet for removing Scraps

Fig 1. shows the scraps lying on the floor in the industry. As this scrap pieces could get pricked in the legs of the worker. This causes a serious health and safety issue in the working environment. The Fig. 2 shows the ergonomically designed magnetic collector to collect the scraps from the shop floor. This is how they remove the scraps in a small scale way. That is, while working if some scraps come on the floor where the worker is standing they remove the scrap using the above shown scrap collector. The magnet is kept on a iron tray. Then the tray gets magnetised. The magnetised tray is rolled over the scraps so that the scraps will get stick to the bottom of the tray. Then when the scrap needs to be released then the magnet is flipped up wards so that the iron tray will get demagnetised and the scrap will be released. Scraps from different machines collected in a container. 


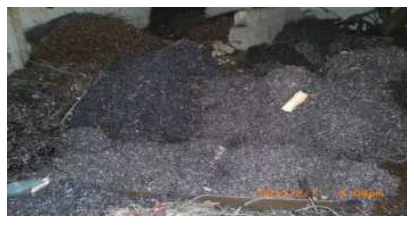

Fig. 3 Scrap Storage

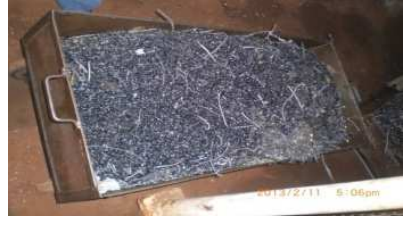

Fig. 4 Tray for carrying Scrap

The scrap is stored in a room with length 6 meter, width 3 meter and height 3 meter. Fig. 3 and Fig. 4 above shows the scrap room and the tray is used to carry the scrap. When the scrap is full in the tray the weight of the scrap is approximately $25 \mathrm{~kg}$. In the room the height of the scrap goes up to 1.5 meter. On a daily basis 2 to 4 trays of scrap are removed from the shop floor. The time taken to remove scraps from the floor is 1.5 to 2 hours on a daily basis.

\section{Force required for compaction}

From literature it is found that the force which is applied for a scrap compactor is 125 Tons for the compressing room size of $1200 * 700 * 600 \mathrm{~mm}$. The force required for the compressing scrap in the new machine of compressing room size $180 * 180 * 180 \mathrm{~mm}$.

$\begin{array}{rlrl} & \mathrm{F}_{1} / \mathrm{A}_{1-} & =\mathrm{F}_{2} / \mathrm{A}_{2} \\ & =\mathrm{F}_{1} / 180 * 180 \quad\left(\mathrm{~F}_{1}=125000 \mathrm{~kg}[4]\right) \\ & =4821.42 \mathrm{~kg} \\ & =4.821 \mathrm{Tons} \\ \mathrm{F}_{1} & & =40 \mathrm{~mm} \\ \text { Cylinder diameter required } & =200 \mathrm{~mm} \\ \text { Stroke Length } & =50 \mathrm{bar} \\ \text { Pressure } & =0-75 \mathrm{bar} \\ \text { Pressure Control Valve (Relief Valve) } & =51 / \mathrm{min}\end{array}$

\section{Scrap Compactor}

A scrap compactor is designed to compress scrap. A screw conveyer will carry the scrap and put it into the cubical space to compress scrap.

\section{Testing of the Circuit in Pneumatics Lab}

The hydraulic and pneumatic techniques use same circuit for the action required for the machine. So the same set up was done in the lab and tested. Fig. 5 above shows the testing arrangement. The circuit consists of a Cylinder and a Direction control valve which is connected in series. Fig 6 shows the circuit diagram required for the machine. The output from the pump is taken and connected to the DC Valve. From the DC Valve the output is connected to the Cylinder. The DC Valve controls the direction of movement of the shaft. 


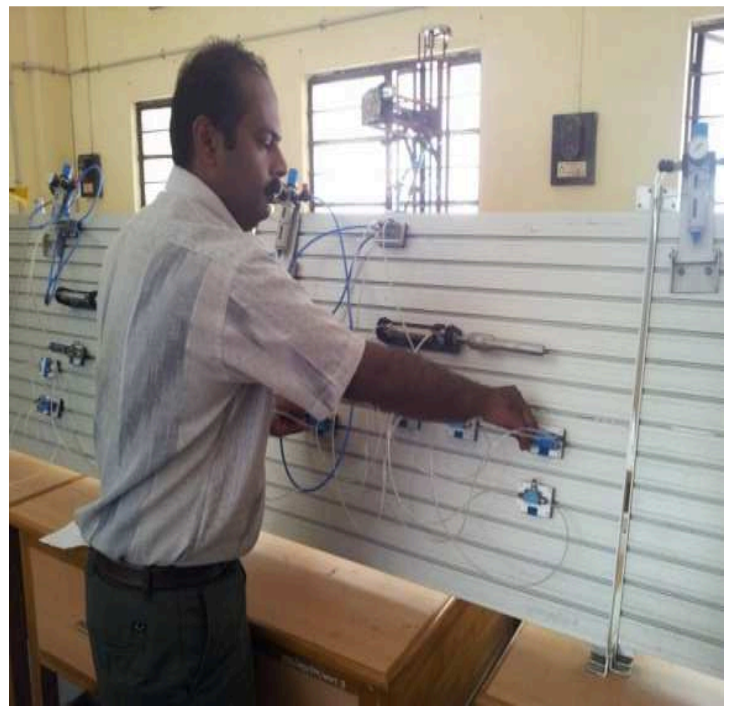

Fig. 5 Circuit Testing

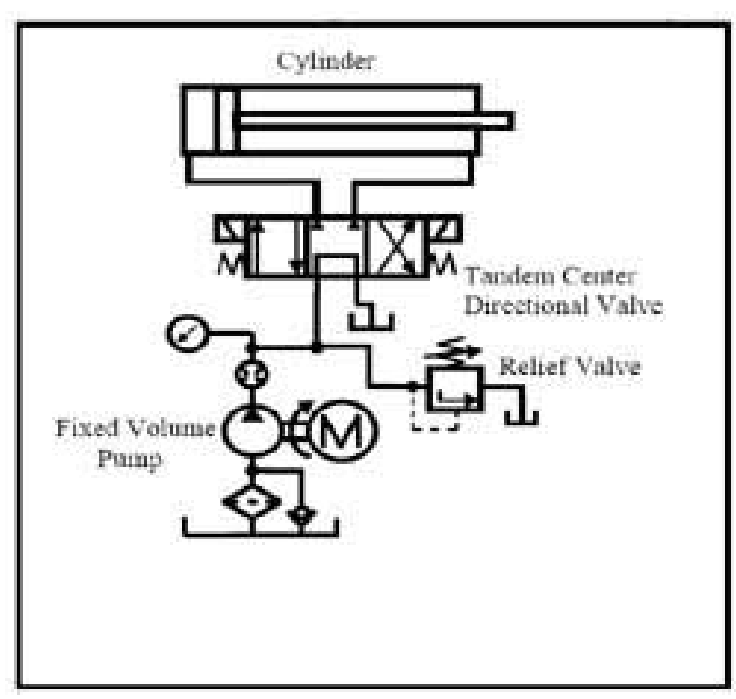

Fig. 6 Diagram of the Circuit

\section{Costing}

Different costs involved in the scrap management are, on a daily basis two helpers of wages Rs 6000/month ( 25 working days) work for 2 hours. A room of size 6 meter long, 3 meter wide and 3 meter height is dedicated for scrap storage.

$$
\begin{aligned}
& \text { Storage Cost }-4000 \mathrm{INR} / \text { month } \\
& \text { Manpower Cost - } 2400 \mathrm{INR} / \text { month }
\end{aligned}
$$

Total Cost of scrap removal and storage is $6400 \mathrm{INR} / \mathrm{month}$. This is the total cost before installing the machine.

The cost of electricity in Tamilnadu for Industries is $8 \mathrm{INR} /$ unit. A 1 Hp motor is 746 Watts. A 1000 Watts motor will consume 1 Unit of electricity in one Hour. So if the power pack has got a motor of 1HP then it will consume 0.746 units of Electricity which will cost $5.968 \mathrm{INR} /$ hour. So the total power consumption cost for a month is 358 INR. From the literature it is found that the compressibility ratio is $5: 1$. So the storage space required after compressing the whole scrap is one $5^{\text {th }}$ of the current space. So the cost of storage will be 800 INR. If we implement the conveyer based scrap compactor then we can assume the number of person working for two hours can be reduced from two to one. So the cost of manpower will become $1200 \mathrm{INR}$ for a month. So if we add these factors then the total cost of scrap removal will become $2358 \mathrm{INR} / \mathrm{month}$. This is less than the half of current cost. The prototype will cost 15000 INR excluding the power pack which costs 30000 INR. The cost savings per month after the installation of the scrap compactor is 4042 INR. So the machine will Break Even in 11 months from its installation.

Individual use of equipment requires flexibility in work organization. Providing freedom for individual variations from the conventional norm acknowledges persons differ in work preferences. The ergonomic design of workstations, their adjustability, and their proper use affect the person's well being and the work performance [8]. Machine ergonomics standards are critical for preventing serious injury from crushing, cutting and thermal exposure. They offer a uniform approach to ergonomic considerations for machine tools within the workplace and assist in design, installation and use of manufacturing systems, including individual and integrated machine tools and auxiliary components [9]. 
CAD Model Developed using Solid-works 2010

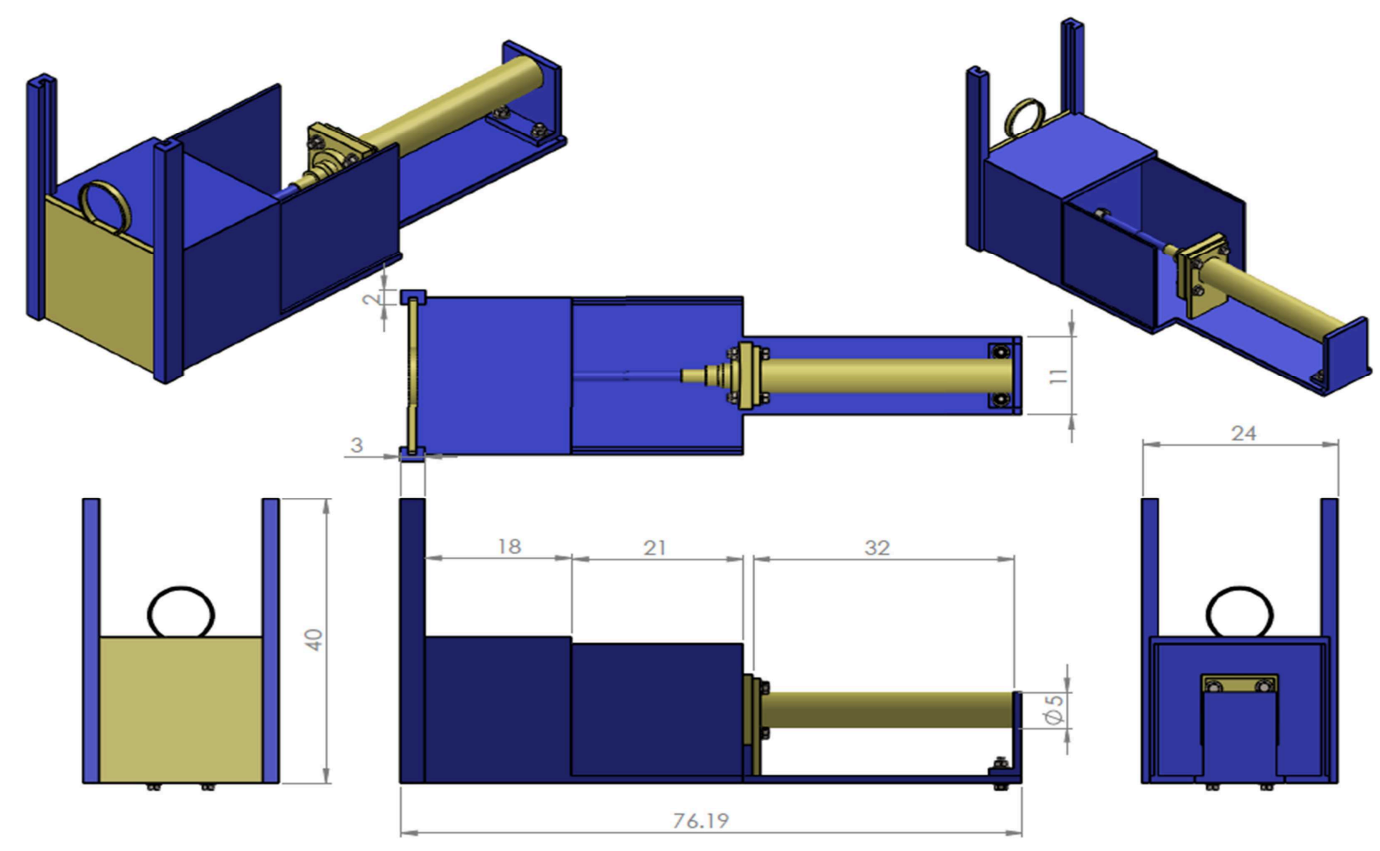

Fig.7 Scrap Compactor

Fig. 7 shows the CAD model developed using Solid-works 2010. It can be seen that the scrap compactor is ergonomically designed. The whole unit can be conveniently shifted to a place adjacent to a machine where more scrap is generated. A screw conveyer (not shown in figure) will be placed above the scrap compactor for feeding the scrap so that the worker need not bend for loading the scrap in the machine which will increase the occupational health of the worker. Since the scrap is compressed before it is transported, it occupies less space and the handling of scrap is easier. The worker's safety is ensured since the scrap is compressed into a solid form. Mechanization of the scrap compactor eliminates the force applied by the worker for compressing the scrap, which is one of the principles of ergonomic design.

\section{Conclusion}

- Ergonomic design of a scrap compactor is shown using a CAD Model.

- The cost of prototype and the cost saving per month are calculated. It is shown that the break even period is 11 months.

- The detailed design of the scrap compactor and finite element analysis are to be performed before carrying out the fabrication of the unit.

\section{Acknowledgement}

The authors thank Mr D. Jayseelan, Managing Director, Vishal Precision Products Pvt. Ltd., for permitting them to carry out this research in their industry. 


\section{References}

[1] Liu Jianxiong, Peng Juntao, Yang Bangcheng, Hou Jie, The Research on Shredding Models of Light Metal Scrap of End-of-life Vehicles and Household Appliances, IERI Procedia, Vol.1, 2012, Pages 146-154.

[2] Technical Training Manual on Hydraulics, TORO University, USA.

[3] S. Darius Gnanaraj, Scrap compression machines- overview, National Seminar on Ergonomics for Enhanced Productivity, Tamilnadu Agricultural University, Madurai, India, (Feb. 18th \& 19th 2013)

[4]Information on http://www.industrysearch.com.au/Scrap-Metal-Baling-Press-SMBF125/p/55463

[5] Information on http://www. hydraulicspneumatics.com

[6] Information on http://www.iqsdirectory.com/balers/

[7] Sieling, Mark Scott, Productivity in Scrap and Waste Materials Processing, Monthly Lab. Rev., 113 (1990), No.4.

[8] Kroemer, K., Kroemer, H., \& Kroemer-Elbert, K. (2001). Ergonomics: How to design for ease and efficiency ( $2^{\text {nd }}$ edition). Englewood Cliffs, NJ: Prentice Hall.

[9] American National Standards Insititute

http://webstore.ansi.org/ergonomics/machine_ergonomics.aspx 